\title{
Electric Vehicle Charging Load Model Based on Diffusion Theory
}

\author{
Han Peng ${ }^{*}$, Jinmei Wu, and Lu Wang \\ School of Mechanical Engineering, North China University of Water Resource and Electric Power, Zhengzhou 450045, \\ China
}

\begin{abstract}
Purpose: discuss actual application value of the diffusion theory in massive electric vehicle charging load.
Method: introduce single vehicle charging process, extend it to charging process of two and multiple electric vehicles, abstract physical process of parallel charging of electric vehicles, introduce energy block concept and diffusion theory, and establish diffusion charging model of electric vehicles based on them.

Results: computing results of the charging load of multiple electric vehicles indicates that the computing results of the diffusion load model of electric vehicles feature better continuity and lower load compared to the computing results of the Monte Carlo load model. The charging load curve of private vehicles shows double peaks on the business days. The charging load of vehicles reduces at the weekend and shows single-peak curve.

Conclusion: the computing results validate effectivity of the diffusion theory in charging model of multiple electric vehicles, which is worthy of further research in industrialization process.
\end{abstract}

Keywords: Diffusion theory, energy block, diffusion load model, load curve, Monte Carlo load model.

\section{INTRODUCTION}

An electric vehicle is a new traffic tool, which his powered by onboard green power, is driven by a motor, and complies with the requirements in road traffic safety, regulations and legal regulations. An electric vehicle has a bright prospect due to its environment influence less than it of a traditional vehicle. Now electric vehicles are divided into pure electric vehicles (EV), hybrid electric vehicle (PHEV) and fuel battery electric vehicles (FCEV). The pure electric vehicle has low speed and its start speed depends on the power and performance of the driving motor. Its travel mileage depends on the capacity of the onboard power battery. The weight of an onboard powerbattery depends on selected power battery such as lead acid, zinc-carbon and lithium battery. Their volume, proportion, specific power, specific energy and cycling life are very different. The hybrid electric vehicles include serial hybrid electric vehicles (SHEV), parallel hybrid electrical vehicle (PHEV) and compound hybrid electrical vehicle (CHEV). The fuel battery vehicles indicate the vehicles powered by the fuel battery. The chemical reaction process of the fuel battery will not generate harmful resultants, so the fuel battery vehicles are ideal in energy utilization and environmental protection [1]. The charging load computing of electrical vehicles is the premise to study influence of electrical vehicles on the power grid and auxiliary application of electric vehicles as the energy storage units on the power market! Now extensively accepted modeling methods include the statistical modeling method based on Monte Carlo simulation and physical modeling method based on actual charging physical process of massive electric vehicles [2] in the research fields on charging load modeling of electric vehicles.

However, related research work indicates that electric vehicle charging has significant influences on the safe operation of a distribution grid and main issues include load, loss, voltage three-phase unbalance, harmonic wave and stability. Disorderly charging of massive electric vehicles will increase voltage peak and valley difference of the power system grid and reduce power supply quality. To reduce or avoid these adverse effects, the charging behaviors of users should be controlled and guided [3, 4]. In addition, some austere challenges are faced in control over electric vehicles under current conditions. If control of electric vehicles is not handled properly, it may lead to explosion of the dimension disaster. It is difficult to make electrical vehicles participate in real-time compensation applications of ACE adjustment power by using the traditional centralized control pattern $[5$, 6]. To deepen discussion on charging load model of massive electric vehicles and optimize research on charging models of current electric vehicles, this paper proposes diffusion load model of electrical vehicles based on diffusion theory in randomness from actual physical charging process of massive electrical vehicles. This model uses parameters affecting power grid quality such as charging power, vehicle quantity, vehicle charge battery capacity, battery initial charging energy, battery end charging energy and charging time in order to discuss actual application value of the diffusion theory in charging load model of massive electric vehicles. 


\section{DIFFUSION LOAD MODEL OF ELECTRIC VEHICLES}

Researchon charging time, initial SOC, battery capacity, charging interval and electric vehicle number is the perquisites to establish a reasonable charging model of electric vehicles. Establishment of charging load model of electrical vehicles aim to study influence disorderly charging of massive electric vehicles on power grid quality, which is also the foundation for making the optimal charging strategy of electrical vehicles and making electrical vehicles participate in auxiliary service of the power market as the energy storage units [7]. To reasonably schedule and control charging behaviors of electric vehicles, this paper deeply studies charging process of two electric vehicles and then mines macro inherent physical process of charging behaviors of massive electric vehicles based on charging process of single electric vehicle.

\subsection{Research on Charging Process of Single Electric Vehicle}

After electric vehicle accumulator is integrated into the power grid, the power grid will charge the accumulator. The power in the accumulator will increase. To describe increase rate of the battery power, the physical parameter "charging power" (P-Charge) is introduced. Compared to the speed definition in the physics, we define the charging power as the derivative of the power to time, namely:

$P_{-} C h \arg e=\frac{d C}{d t}$

$\mathrm{C}$ is the battery power.

From the equation 1, the charging time is:

$T=\int_{C_{\min }}^{C_{\max }} \frac{1}{P_{-} C h \arg e} d C=\frac{C_{\max }-C_{\min }}{P_{-} C h \arg e}$

For generality, if P_Charge is a constant, namely the electric vehicles are charged at constant power, the charging time is

$\frac{C_{\max }-C_{\min }}{P_{-} \text {Charg } e}$

The charging process is shown as the Fig. (1).

From the above Fig. (1), the battery power $\mathrm{C}$ is the time function of the charging power $\mathrm{P}_{-}$Charge and the tangent slope of the battery power $\mathrm{C}$ at different time points is the charging power. If the charging process is divided into $\mathrm{K}$ equal portions, the time of each "portion"is $\frac{T}{K}$. The power increases by $\frac{C_{\max }-C_{\min }}{K}$ and $P_{-} C h \arg e \cdot \Delta t=\Delta C$.

The charging process of single electric vehicle can be abstracted as a diffusion process of an assumed molecule from low energy section to high energy section. Assuming that the molecule diffuses to ith energy section, the current charging power of the accumulator is $\mathrm{i}^{*} \Delta \mathrm{C}$. When $\mathrm{i}=\mathrm{K}$, charging ends and the electric vehicles are disconnected from the powergrid.

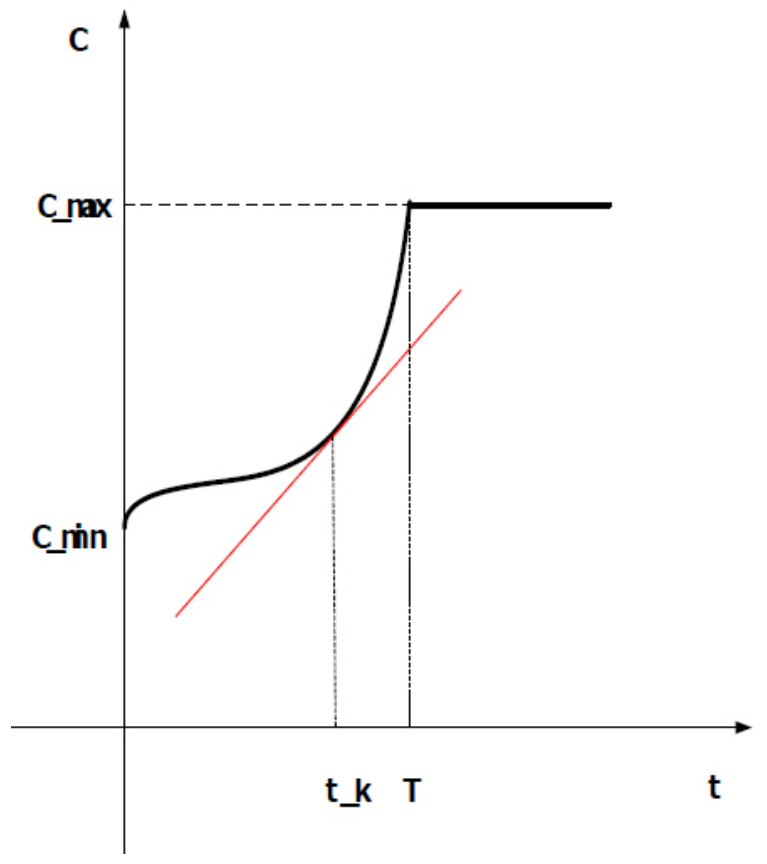

Fig. (1). The charging process.

\subsection{Research on Charging Process of two Electric Vehicles}

Charging process of single electric vehicle is a relatively simple physical process, but this process is the foundation to study macro physical process of parallel charging of massive electric vehicles. In addition, to model the charging load of electric vehicles, it is required to analyze association of random parallel charging behaviors of two electric vehicles. To simplify charging process of electric vehicles, the charging power of each electric vehicle is set as a constant. For generality, assuming that the first electric vehicle is in charging and the second electric vehicle is in parallel charging, shown as the Fig. (2).

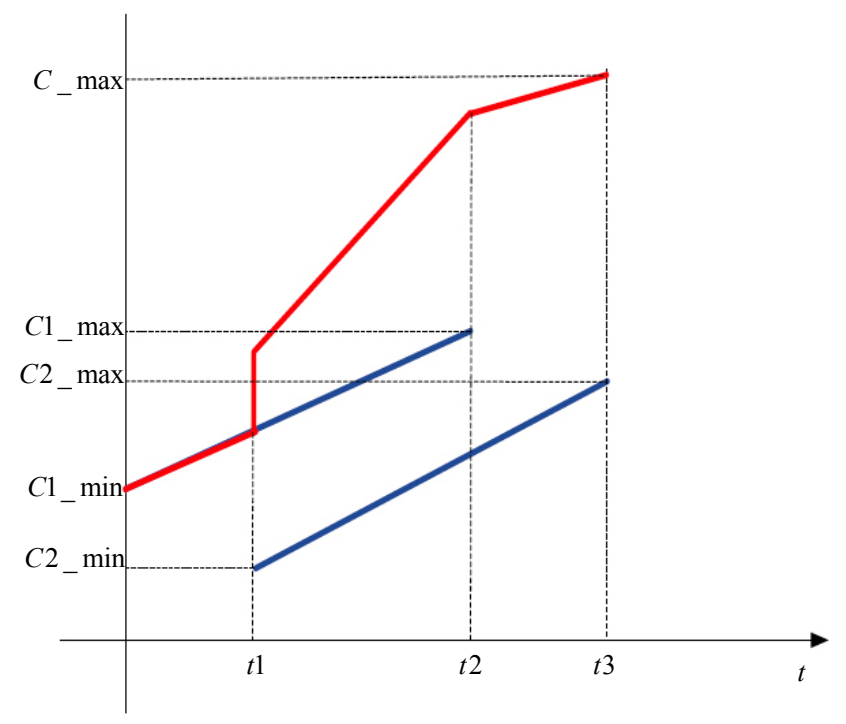

Fig. (2). Charging process of two electric vehicles.

The above figure indicates that the electric vehicle 1 is charged at the time 0 and charging ends at the time t2. The 
electric vehicle 2 is connected to the power grid at the time t 1 and charging ends at the time 3 . Only the electric vehicle 1 is under charging status at the interval 0 -t1. The power grid will start to charge two elective vehicles simultaneously at the interval $t 1-t 2$. The elective vehicle charging ends at the interval $\mathrm{t} 2$-t 3 . The power grid only charges the elective vehicle 2. The general physical process of parallel charging of two elective vehicles is still described by using the assumed molecule diffusion in the energy block. At this time, two elective vehicles are equivalent to "one assumed molecule". If the second elective vehicle is connected to the power grid at the time $\mathrm{m}$, the whole charging power is shown as the following equation:

$$
\begin{aligned}
& P_{-} C=P_{-} C h \arg e^{*} Q= \\
& P_{-} C h \arg e \times\left[\begin{array}{l}
1 \\
1 \\
\cdots \\
1
\end{array}\right]_{1 \times(K+m-1)} \times\left(\left[\begin{array}{l}
E \\
O
\end{array}\right]+\left[\begin{array}{l}
O \\
E
\end{array}\right]\right)
\end{aligned}
$$

$\mathrm{E}$ is the unit matrix with the diagonal as $1 . \mathrm{O}$ is the (m$1)^{*} \mathrm{~K}$ zero matrix. When the general charging load of the power grid for two electric vehicles is computed in parallel charging, total electric vehicles should be computed in the energy blocks at this time and be multiplied with the charging power. The total charging power of electric vehicle at the time iis described as follows:

$$
P_{-} C(i)=P_{-} C h \arg e^{*} \sum_{j} Q(j, i)
$$

\subsection{Establishment of Diffusion Load Model of Electric Vehicles}

To simplify the model, we assume that the battery capacity and charging power of electric vehicles are same. $\mu(t)$ is the wide-area control signal sent by the scheduling center to parallel electric vehicle and $\mathrm{P}_{-} \max$ is the maximum controllable charging power. To compare the parallel charging process of two electric vehicles in 2.2, the multielectric vehicle charging model extends single electric vehicle charging model. New molecules will continuously join in the energy blocks when massive assumed molecules diffuse forward. When all assumed molecules have joined into the energy block and diffuse to the final energy block, diffusion process will end. If the number of the electric vehicles connected to the power grid is a continuous function, the charging power of the power grid is described as follows:

$$
\begin{aligned}
& P_{-} C=P_{-} C h \arg e * Q \\
& =P-C h \arg e \times\left[\begin{array}{l}
1 \\
1 \\
\ldots \\
1
\end{array}\right]_{1 \times(K+K-1)} *\left(\omega_{1} *\left[\begin{array}{l}
E \\
O_{1}
\end{array}\right]_{(K+K-1) \times K}+\omega_{2} *\left[\begin{array}{l}
E \\
O_{22}
\end{array}\right]_{(K+K}\right.
\end{aligned}
$$

$\omega_{i}$ is the number of the electric vehicles connected to the power grid at ith time and $O_{i j}$ is zero matrix.
From $\omega_{i}$ definition, the total electric vehicles connected to the power grid at the time $i$ is:

$Q(i)=Q(i-1)+\omega(i)=\sum_{i} \omega(i)$

Based on the above statement, to differentiate multiple electric vehicles, one-order partial differential linear diffusion equation can be obtained:

$$
\left\{\begin{array}{l}
\frac{\partial Q(c, t)}{\partial t}=\omega(c, t)-\frac{\partial Q(c, t)}{\partial t}\left(P_{1}+P_{\max } * \mu(t)\right) \\
P_{-} C_{(}(t)=\left(P 1+P \max ^{*} \mu(t)\right) \int_{C_{-} \min }^{C_{-} \max } Q(c, t) d c \\
Q\left(C_{-} \min , t\right)=0 \\
Q\left(C_{-} \max , t\right)=0
\end{array}\right.
$$

The equation 7 is the diffusion load model of electric vehicles.

\section{COMPUTING OF CHARGING LOAD OF MULTIPLE ELECTRIC VEHICLES}

The electric vehicles are divided by purpose into private vehicle, taxi, state-financed vehicle and bus in this paper. Based on report in the reference [8], battery features, charging time and frequency of different electric vehicles are different. Generally the taxi, state-financed vehicles and buses have inherent driving features and charging sites. The charging load demand is fixed. The driving mileage and charging behaviors of private vehicles are random and flexible. The charging sites and charging types of private vehicles are relatively complicated, so this paper mainly studies private vehicles and discusses its charging feature:

\subsection{Driving and Charging Features of Private Electric Vehicles}

Private electric vehicles are mainly used for on-duty, offduty and entertainment and corresponding charging sites include office parking lot, residential parking lot and supermarket parking lot. When the private vehicles stop at the unit's parking lot and residential parking lot, they will be charged for a long period, so electric vehicles can be charged fully and this case is the type 1 charging behavior. The supermarket parking lot is restricted by the charging duration and this case is the type 2 charging behavior [9, 10]. The charging sites and charging type of electric private vehicles is shown as the Fig. (3).

It is assumed that the private vehicle is charged once every day. The start SOC meets normal distribution $\mathrm{N}(0.6$, 0.22 ). The ratio of the private vehicles charged prior to 00:00 hour to the private vehicles charged after 00:00 hour is 5:1 at the weekend. The natio of the private vehicles charged at the resident parkiog slot, company parking and supermarket parking slot is $6: 3: 1$. The on-duty arrival time of the private vehicles is centralized compared to the off-duty home time and on-duty and off-duty time of differentcompanies are different. Assuming that the start charging time of the private vehicles at the company parking lot and resident parking obeys normal distribution $\mathrm{N}(10,0.52)$ and $\mathrm{N}(20,1.52)$. The 


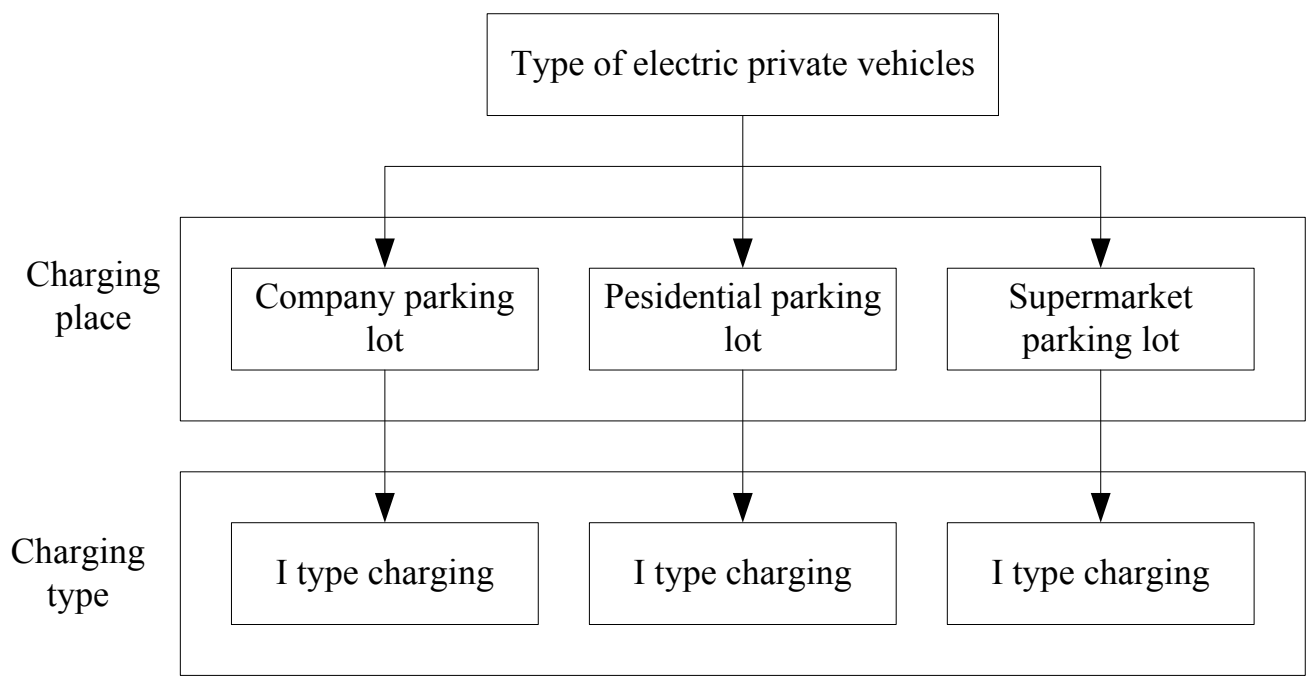

Fig. (3). Charging site and charging type of private vehicles.

start charging time of type I charging and type II charging obeys uniform distribution. The battery capacity parameters of all private vehicles refer to the parameters of BYD E6. The rated voltage of the used lithium battery is $320 \mathrm{~V}$ and the rated capacity is $200 \mathrm{~A} \bullet \mathrm{h}$. The normal and fast charging power are $14 \mathrm{KW}$ and $90 \mathrm{KW}$. The assumed charging features of the private vehicles in this model are shown as the Table 1.

\subsection{Monte Carlo Load Model}

The charging behaviors of electric vehicles are not certain. The charging power is a random variant, which value depends on the battery features, charging time and charging mode. The Monte Carlo load model is one frequent model in the traditional charging load computing models.

The Monte Carlo (MC) method is also called as the statistical simulation method and random sampling technology, which is based on the probability and statistics theory method and solves many computing problems by using a random number (or frequent pseudo random numbers). Generally the solved problems are associated with certain probability model. Electronic computers can realize statistics simulation or sampling to get the approximate solutions of the problem. When the reliability features of different companies are known, but the system reliability is

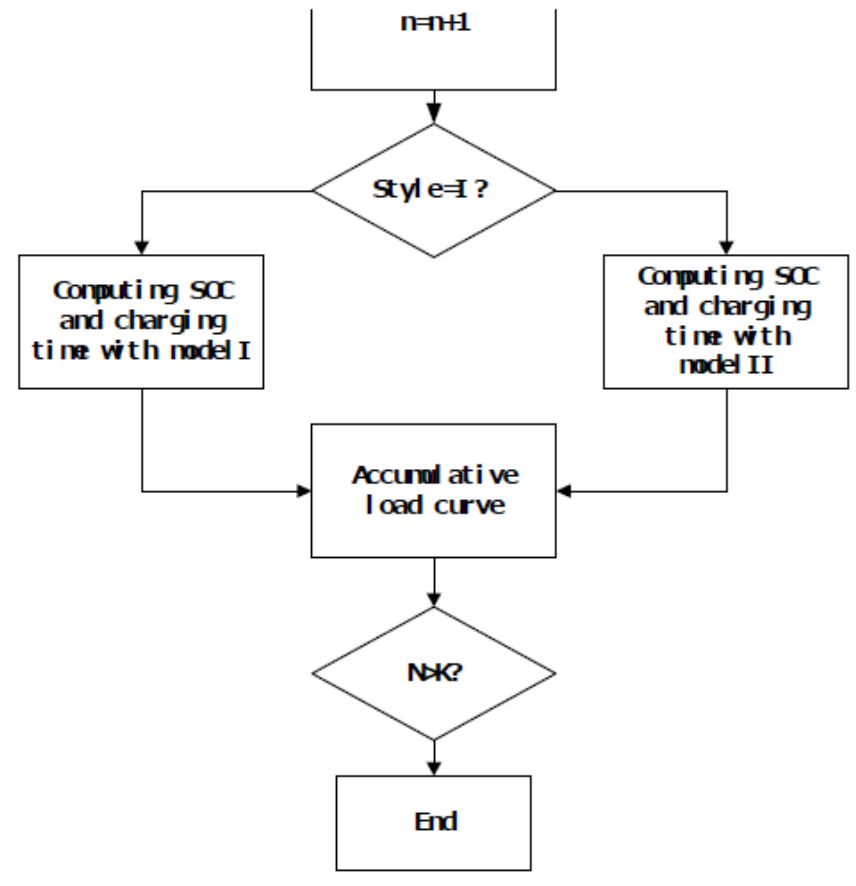

Fig. (4). Monte Carlo computing flowchart.

too complicated, so it is difficult to establish a precise mathematical model for reliable prediction or the model is

Table 1. Charging features of private electrical vehicles.

\begin{tabular}{|c|c|c|c|c|c|c|}
\hline $\begin{array}{l}\text { Charging } \\
\text { Type }\end{array}$ & $\begin{array}{c}\text { Daily Charging } \\
\text { Time (n) }\end{array}$ & $\begin{array}{l}\text { Charging } \\
\text { Interval }\end{array}$ & $\begin{array}{l}\text { Charging Duration is } \\
\text { Restricted or Not }\end{array}$ & $\begin{array}{c}\text { Charging Probability } \\
\text { Different Intervals }\end{array}$ & $\begin{array}{c}\text { Start SOC } \\
\text { Distribution }\end{array}$ & $\begin{array}{l}\text { Start Time } \\
\text { Distribution }\end{array}$ \\
\hline \multirow{3}{*}{ Business day } & \multirow{3}{*}{1} & $7: 30-17: 30$ & No & 0.3 & $\mathrm{~N}(0.6,0.22)$ & $\mathrm{N}(10,0.52)$ \\
\hline & & 19:00-7:00 & No & 0.6 & $\mathrm{~N}(0.6,0.22)$ & $\mathrm{N}(20,0.52)$ \\
\hline & & $19: 00-22: 00$ & $80 \mathrm{~min}$ & 0.1 & $\mathrm{~N}(0.6,0.22)$ & Uniform distribution \\
\hline \multirow{3}{*}{ Weekend } & \multirow{3}{*}{0.8} & $20: 00-5: 00$ & No & 0.5 & $\mathrm{~N}(0.6,0.22)$ & Uniform distribution \\
\hline & & $0: 00-7: 00$ & No & 0.1 & $\mathrm{~N}(0.6,0.22)$ & Uniform distribution \\
\hline & & $12: 00-22: 00$ & $80 \mathrm{~min}$ & 0.2 & $\mathrm{~N}(0.6,0.22)$ & Uniform distribution \\
\hline
\end{tabular}


too complicated and can't be applied. A random simulation method is used to approximately compute the predicted value of system reliability. With growth of simulation time, precision will gradually increase. The Monte Carlo simulation is used as charging load computing method of electric vehicles for the start SOC of the sampled company vehicle and start charging time.

\subsection{Computing Results of Charging Load of Electric Vehicle}

To discuss validity of diffusion theory in charging load model of massive electric vehicles, this paper studies the diffusion load model of electric vehicles by selecting different electric vehicle scales and charging types and compares the result with them of Monte Carlo load model. The computing results are shown as the Fig. (5).

The Fig. (5a) is the charging load curve of a business day for 10000 electrical vehicles connected to the power grid. The Fig. (5b) is the charging load curve of a business day for 20000 electrical vehicles connected to the power grid. The Fig. (5c) is the charging load curve of weekend days for 10000 electrical vehicles connected to the power grid. The red solid line indicates the computing results of the diffusion load model of electric vehicles. "*" indicates the computing results of the Monte Carlo load model.
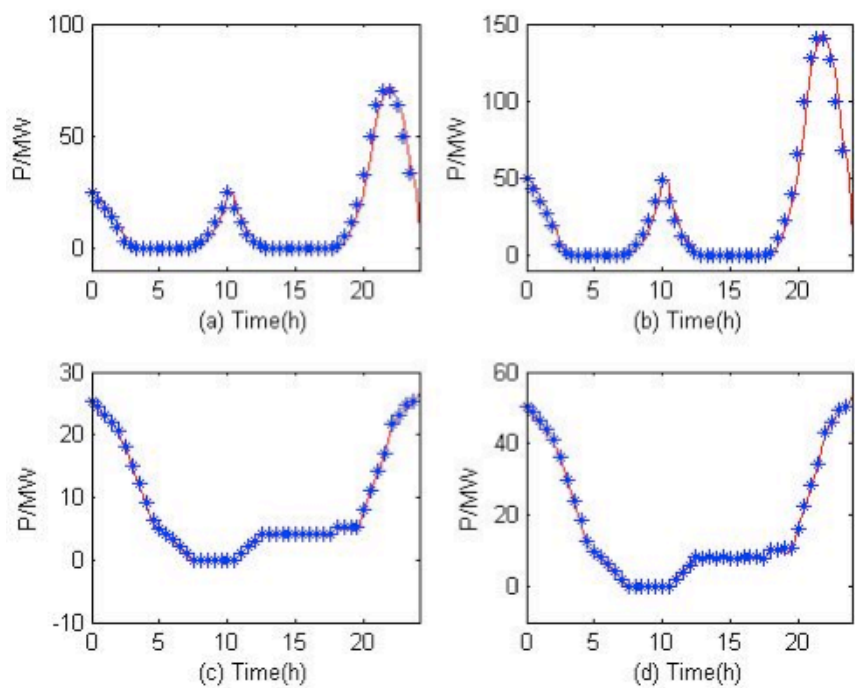

Fig. (5). Charging load curve of private vehicles.

The above figure indicates that the charging load has different features due to different use habits of the private vehicle owners on the weekend and business days. The computing results of the diffusion load model of electric vehicles are same as them of the Monte Carlo load model and the load is smaller than it of the Monte Carlo load model. In the Fig. (5a, b), the charging load curve will have double peaks, namely the private vehicle owners may charge vehicles at the companies and the charging occurs at the company parking lot and resident parking lot. For the Fig. $(\mathbf{5 c}, \mathbf{d})$, the private vehicle owners do not work at the weekends, so the vehicles will reduce, the start SOC of the private vehicle is high, and the charging time reduces. At this time, the charging mainly occurs at night at the resident parking lot. Notice that a small number of private vehicles are in charging at the interval $12-20$ due to supermarket charging. In addition, when the vehicles connected to the power grid increase, the charging power will grow.

\section{CONCLUSION}

This paper starts with charging process of single vehicle and then extends to charging of two vehicles and multiple vehicles. This paper abstracts the physical charging process of electrical vehicles in the power grid, introduces diffusion theory, and establishes the electric vehicle diffusion load model based on it. This model is different from the traditional charging load model. The traditional model computes the load based on discrete load accumulation or statistical simulation accumulation. The model proposed in this paper mainly uses the continuous differential method. The computing results of charging load of multiple electric vehicles indicate that the computing results of diffusion model of electric vehicles features better continuity and lower load compared to the Monte Carlo model. The charging curve of the private vehicle has double peaks at the weekend. The charging load will reduce at the weekend and display as single-peak curve. When the electric vehicles connected to the power grid increases, the charging power will grow.

Electric vehicles are quickly developing and the involved aspects are extensive. A large number of electric vehicles are connected to the power grid irregularly, so it brings an austerechallenge to the power supply quality. This paper applies the diffusion theory in charging load model of multiple electrical vehicles. Now this work is on research phase and many weaknesses should be further improved. The fact proves that the multiple electric vehicle charging model based on the diffusion theory features better computing continuity and lower load. It is expected that the research can explore application of the diffusion theory in electric vehicle charging.

\section{CONFLICT OF INTEREST}

The author confirms that this article content has no conflict of interest.

\section{ACKNOWLEDGEMENTS}

Declared none.

\section{REFERENCES}

[1] K. H. Guo, "Thinking on industrialization of electric vehicles in China”, China Engineering Science, vol. 13, no. 9, pp. 4-7, 2011.

[2] F. J. Sun and G. L. Yin, "Discussion on distribution grid load rate of electric vehicles", Science and Technology Innovation Herald, vol. 13, pp. 42, 2011.

[3] L. P. Fernandez, T. G. S. Roman, and R. Cossent, "Assessment of the impact of plug-in electric vehicles on distribution networks", IEEE Trans on Power Systems, vol. 26, no. 1, pp. 206-213, 2011.

[4] S. L. Anderson, A. K. Elofsson, and M. D. Galus, "Plug-in hybrid electric vehicles as regulating power providers: case studies of Sweden and Germany", Energy Policy, vol. 38, no. 6, pp. 27512762, 2010.

[5] W. Kempton and T. Kubo, "Electric-drive vehicles for peak power in Japan”, Energy Policy, vol. 28, no. 1, pp. 9-18, 2000. 
[6] Z. W. Luo, Z. H. Hu, and Y. H. Song, "Computing method of electric vehicle charging load", Power system Automation, vol. 35, no.14, pp. 36-42, 2011.

[7] D. S. Callaway, "Tapping the energy storage potential in electric loads to deliver load following and regulation, with application to wind energy", Energy Conversion and Management, vol. 50, pp. 1389-1400, 2009.

[8] W. Zhou, F. B. Wu, and Z. H. Liu, Intelligent centralized charging strategy of plug-in hybrid electrical vehicles in real-time power price", Power System Automation, vol. 35, no. 14, pp. 62-67, 2011.
[9] H. L. Li and X. M. Bai, "Influence of electric vehicle charging on distribution grid and its countermeasure", Power System Automation, vol. 35, no. 17, pp. 38-42, 2011.

[10] M. Galus, S. Koch, and G. Anderson, "Provision of load frequency control by PHEVs, controllable loads and a co-generation unit", IEEE Trans on Industrial Electronics, vol. 58, no. 10, pp. 45684582, 2011.

(c) Peng et al.; Licensee Bentham Open.

This is an open access article licensed under the terms of the Creative Commons Attribution Non-Commercial License (http://creativecommons.org/licenses/by-nc/3.0/) which permits unrestricted, non-commercial use, distribution and reproduction in any medium, provided the work is properly cited. 